\title{
Formas y significados del vestido en una sociedad posmoderna: el caso de San Salvador*
}

Mariella Hernández Moncada Melissa Regina Campos

Entre las formas de cultura creadas por el ser humano en sociedad está el modo de vestir, $y$, a pesar de que necesidades funcionales del vestido varían de una sociedad o región a otra al encontrarse presente en todas y cada una de ellas, esto lo vuelve un hecho universal. Ciertamente, la vestimenta surge con la básica finalidad de dar respuesta a la necesidad de abrigo. Y si el uso de la vestimenta es universal, lo que la hace diferente en cada grupo humano es el desarrollo independiente de sus propios patrones, llegando incluso a ser uno de los fuertes rasgos identitarios de cada grupo social. Así, el estudio del vestido no puede separarse del entorno cultural al cual pertenece, pues sus formas básicas se aplican a unos cánones o normas impuestas por la cultura misma.

\section{Vestirse para...}

Desde sus más remotos orígenes, el simple acto de vestirse se ha presentado como una necesidad de abrigo, y que para ello los humanos hoy y en el pasado han procurado vestirse según sus necesidades medio- ambientales y preferencias. Esto parece algo "evidente", que no merece reflexión. Sin embargo, desde el punto de vista antropológico, una característica importante de la vestimenta es que las formas culturales de su uso han condicionado la necesidad de hacerlo. Una prueba de este fenómeno es la diversidad de formas que toma el vestido según los sistemas prácticos que señalan qué ropa ponerse y cuál no, cuándo usar ciertas prendas o quiénes deberían usarlas según sectores, edades y géneros. Así, existen "ropa de ricos” (según marcas), ropa de pobres ("bajera”, de imitación), ropa femenina y masculina (blusa y camisa), también hay ropa "apropiada" para niños, para adolescentes, para adultos y para ancianos.

\footnotetext{
* Resumen de la tesis para optar el grado de Licenciatura en Antropología.
} 
Lo cierto es que, apenas empezamos a reflexionar, observamos la red de significación implícita en la vestimenta. Si es considerada "buena" o "mala"; "vestirse bien", es decir, tener acceso a toda clase de ropa y ornamentos "caros"; o bien, de acuerdo con normas culturales de combinar las prendas con el cuerpo, el tiempo, el espacio y el contexto. Vestirse "mal" porque lo hace sin cumplir estas normas, o porque sus ropas son "baratas" y de "mal gusto". Vestirse para... Más que descifrar el por qué - la causa por la que la gente se viste - , es importante resaltar para qué, pues esta fórmula indica la relación del vestido con un sinfín de hechos sociales propios de la cultura, lo ulterior al vestido. Más que un pedazo de tela, a este se le imponen las normas culturales de un grupo determinado. Las categorías sociales que dan forma al material textil para convertirlo en vestido están presentes de una manera tan silenciosa que no se las percibe como tales. Por eso - como ya se ha señalado - es que se considera el acto del vestir como un hecho "normal".

El vestido no se usa solo para cubrirse. En este medio sociocultural se puede afirmar que la gente se viste para indicar el género, iniciar y mantener relaciones personales o de negocios, marcar el sello de la individualidad, proclamar la distinción y demostrar la pertenencia a un grupo, señalar el status social, reforzar la autoestima y ganar reconocimiento, manifestar una preferencia política, demostrar creencias religiosas, transmitir seguridad, expresar sentimientos morales, como medio de propaganda comercial, jactancia de riqueza, designar oficios o profesiones, como instrumento de seducción y cortejo, etc.

\section{La mirada del otro}

El otro es una mirada de la cual soy objeto.

Jean Paul Sartre

La mirada es hoy el sentido hegemónico de la vida social urbana. La gente se viste cayendo en la cuenta de que está presente ante otros. Ante esa mirada del otro se configura su exterioridad como expresión de lo que es. La gente entonces constituye una "identidad" desde la alteridad, desde la mirada del otro que lo objetiva, que le otorga consistencia a su ser. El vestido es un texto, (un discurso) que debe ser leído, que se dirige a alguien. En la esencia de la ciudad se ha detectado una fuerte tendencia a "mirarse" con diferentes proxe- 
mias, según el lugar. Los centros comerciales que sobreexponen el nuevo espacio social es donde se hace más evidente esta "cultura visual”, pues son los escenarios donde se representa el vestido como espectáculo que lucir.

El lenguaje de la vestimenta es asimilado por medio de la vista. Al ser un código visual y espacial, y al estar fuertemente condicionado por la mirada de los demás, el vestido se advierte como una envoltura expresiva y significativa del sujeto, permitiendo entonces afrontar la mirada de los otros. En algunos casos busca complacerla y, en otros, desafiarla. El vestido señala además la actitud hacia los demás. Vestirse implica hacerlo en el marco de las relaciones sociales con los demás.

\section{Vestimenta y seducción:}

"Sex in the sívar"

Si el vestir es una invitación al diálogo, es más precisamente al diálogo que se busca. Por lo tanto, existen estrategias a través del vestido como medio expresivo para competir con éxito en el mundo de la seducción. En la socie-

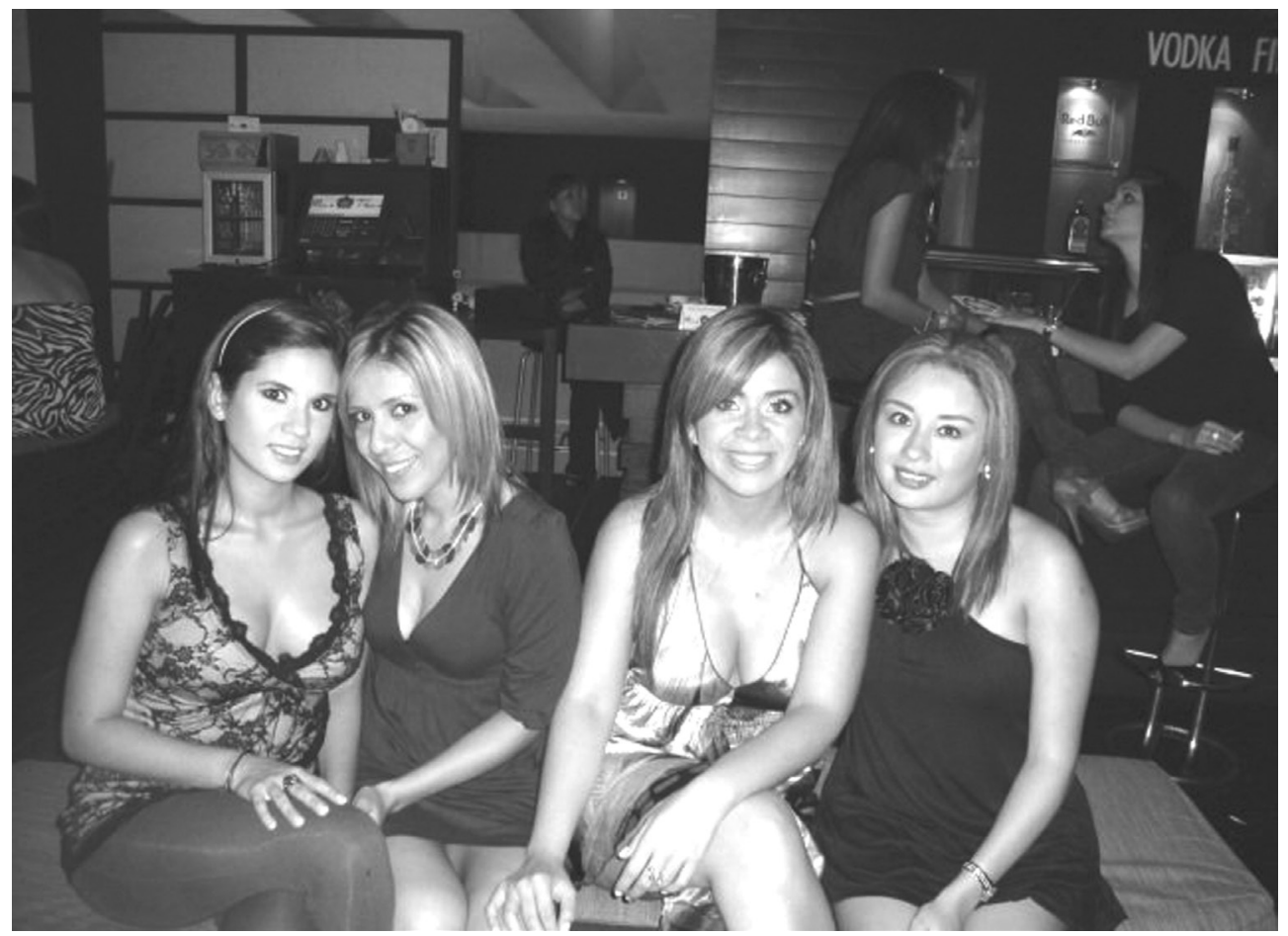

En la sociedad salvadoreña, exhibirse a través de la forma de vestir es un medio para destacar partes del cuerpo que se califican como" deseables" y que son importantes para los rituales de cortejo. 
dad salvadoreña los rituales de cortejo amoroso se caracterizan por que las mujeres, al alcanzar la edad núbil, ven prolongarse su adolescencia en la que deben exhibirse, pavonearse y adornarse con sus mejores galas para resultar "deseables". Mientras que los hombres se limitan a contemplarlas y no tienen tanta "obligación" de esmerarse en su arreglo personal o seguir la moda.

El vestido, como medio de seducción - en el caso de las mujeres -, muchas veces está relacionado con el hecho de "mostrar" sus atributos físicos. Poseer "un buen cuerpo" constituye uno de los grandes ideales asociados a la feminidad. La búsqueda de una relación amorosa se hace, entonces, por medio de la valoración de los signos de la vestimenta como un medio que permite destacar las formas físicas. El sistema de la moda está al servicio de las relaciones de seducción y dicta los modelos específicos para dicha acometida, creando el "vestido seductor" femenino (prendas ajustadas al cuerpo, grandes escotes, pantalones de talle bajo, uso de telas semitransparentes, shorts, minifaldas); y masculino (los símbolos de estatus para poner en evidencia su carácter de ser un "buen partido").

Sin embargo, existe una ambivalencia: mientras que por un lado se incita a las mujeres a ser atractivas, a cuidar su cuerpo y mostrarlo como signo de su belleza; por otro, puede acusárselas de "provocativas", "fáciles" o "zorras". Además, los signos tradicionales de lo masculino y lo femenino, en cuanto a vestuario y ornamentos se refieren, tienden a intercambiarse alimentando el tema de lo andrógino, reinventando así el concepto de viril. El hombre "metrosexual", que al igual que la mujer suele estar inmerso en la cultura de la moda, cuida su look y es asiduo a los salones de belleza.

\section{Los ajuares de la ideología:}

\section{¡El pueblo, bien vestido, jamás será vencido!}

La esquina "del Frente" - como se le conoce popularmente - está ubicada sobre la calle Rubén Darío. Esta esquina se especializa en comercializar artículos propios de la cultura de "izquierda": música de protesta, películas y documentales de la "guerra"; camisetas del Che Guevara, de monseñor Romero, de Shafick Handal; pulseras, llaveros, pañoletas, bolsos, gorras, etc.; todas portando un estampado o bordado de los llamados "símbolos globales y locales del antisistema". 


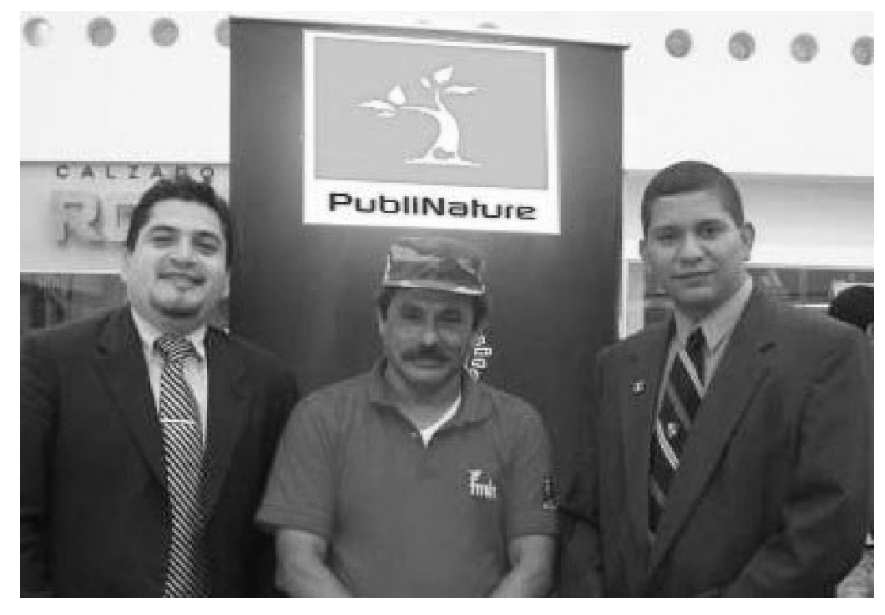

la indumentaria puede expresar también la afiliación política y el carácter de militancia o simpatía por una institución política.
Símbolos antisistema.

Son aquellos personajes, logotipos, palabras, dibujos, etc., que representan la oposición al y disconformidad con el sistema capitalista, la globalización y el neoliberalismo en un carácter mundial; y a las políticas gubernamentales del partido en el poder en un carácter local.

\section{Símbolos globales.}

Rostros de personajes emblemáticos: Che Guevara, Fidel Castro, Bob Marley, Hugo Chávez, subcomandante Marcos, entre otros; banderas y símbolos de países: Venezuela, Cuba; la hoz y el martillo.

\section{Símbolos locales.}

Rostros de personajes: monseñor Romero, Shafick Handal, Farabundo Martí; las letras blancas sobre un fondo rojo con las siglas "FMLN".

Estas prendas se encuentran diseminadas por todo el centro de San Salvador. Sin embargo, también pueden encontrarse en Plaza Mundo y en La Gran Vía. Esto no provoca una reacción de rechazo entre otras personas, es considerado hasta cierto punto normal. De hecho, algunas tiendas comercializan camisetas de Bob Marley (símbolo antisistema asociado también al rastafarismo). En otro nivel social, es decir, más elevado económicamente, las prendas que se comercializan tienen un coste más elevado y usan mayoritariamente los símbolos globales y no los locales. El uso de prendas "antisistema" expresan tres cosas: 1) descontento con las políticas gubernamentales y rechazo a las corrientes neoliberales; 2) adhesión a una alternativa global que rechaza el capitalismo y la globalización, y 3) atracción psicológica a una imagen que seduce y genera sentimientos "revolucionarios". 


\section{Vestiduras religiosas:}

\section{"Señor, perdónalos porque no saben lo que visten"}

Tradicionalmente en El Salvador la asistencia a la ceremonia religiosa se ha caracterizado por el recato y la elegancia. De ahí podemos decir que las que llamamos "vestiduras religiosas" tienen un carácter utilitario: se usa para la misa o para el culto. La fe católica tiene principalmente el velo negro de las mujeres, el chal y accesorios tales como escapularios, medallas y rosarios como prendas exclusivamente religiosas. No olvidando los vestidos de primera comunión, de bautizo, de boda y de velorio, entre otros.

La iglesia católica, en tiempos recientes, ha hecho de la camiseta un instrumento de identificación entre sus miembros, especialmente de movimientos parroquiales, quienes de manera independiente mandan a hacerlas solo para uso de sus miembros, sin perjuicio que puedan regalarlas a personas amigas. Se ha hecho común también portar camisetas con la imagen de "Monseñor Romero", mártir de la fe católica. Su imagen se comercializa junto a la imagen de la Virgen María, de Cristo, de diversos santos, de Juan Pablo II, etc. Monseñor Romero - o al menos su uso en prendas de vestir tan generalizado - representa una conjunción entre política y religión: "Entre Cristo y el Che, hace de arbitro monseñor".

Por su parte las iglesias pentecostales han hecho lo propio: camisetas que identifican a los miembros del "Castillo el Rey", "Iglesia Peniel", "Hombre de Cristo", "León de Judá", que se comercializan en diferentes locales, tanto de Plaza Mundo como del Centro de San

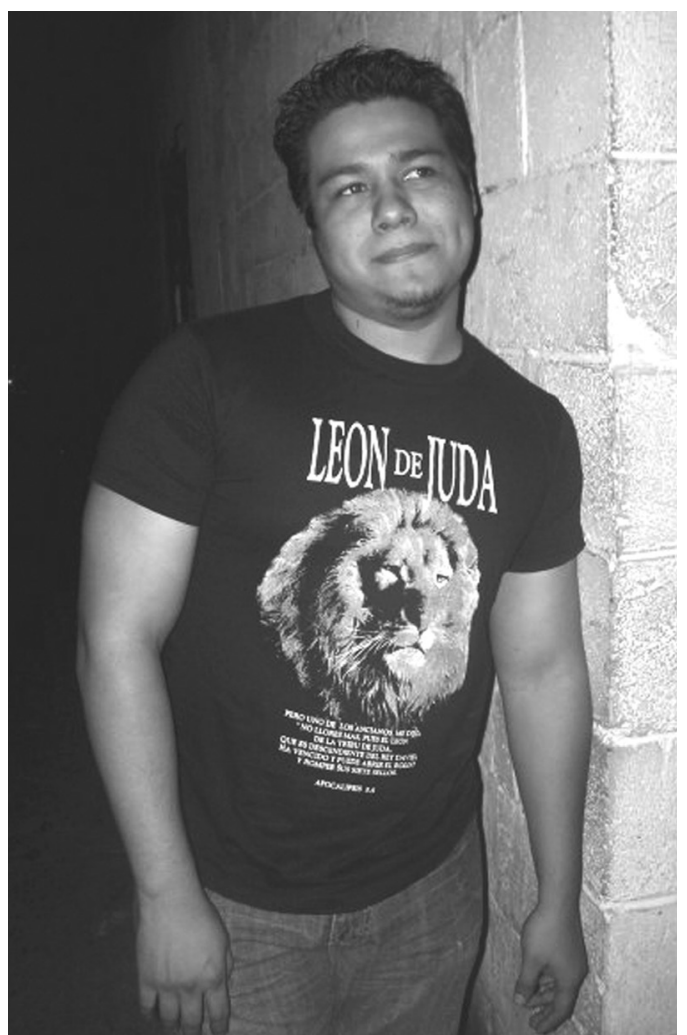

Las religiones han hecho de la comercialización de camisetas una insignia de sus adeptos. 
Salvador. Los "evangélicos" pueden llevar sus signos distintivos a extremos insospechados. Dos casos merecen mencionarse: el de la iglesia Elim y el del Tabernáculo Bíblico Bautista.

La iglesia Elim ha llamado durante años la atención de los salvadoreños. Un solo detalle les caracteriza: el uso del pañuelo blanco en la cabeza por parte de las mujeres. En los hombres suele notarse una especie de "orden" en la disposición de su ropa: camisa manga larga siempre por dentro, pantalón de vestir, zapatos de vestir; las mujeres, falda muy por debajo de las rodillas y su pañuelo blanco en la cabeza.

El Tabernáculo Bíblico Bautista ha sido bastante más agresivo al distinguir a sus miembros a través de prendas propias de su Iglesia: las mujeres usan falda celeste debajo de las rodillas, blusas con una cinta roja atada al cuello, manga larga, y un pin propio de la Iglesia; algunas llevan un pañuelo rojo en el cue1lo. Por su parte, los hombres usan saco y corbata y el pin. Las dos grandes religiones que existen en El Salvador han usado la vestimenta como un medio de identificación de sus miembros.

\section{Vestirse para el éxito: "El hábito sí hace al monje"}

Desde que el niño está en la más temprana etapa de escolaridad aprende a relacionar profesiones con vestiduras propias de cada una. Sin embargo, en una sociedad posmoderna donde surge innumerable cantidad de nuevos oficios las costumbres se relajan en algunos casos y, en otros, se tornan rígidas. Este tipo de asociación oficios-uniforme se torna poco práctica. En nuestros días existen asociaciones relacionadas con la vestimenta y con el trabajo. Estas asociaciones podrían ser de éxito o de fracaso.

La cultura occidental ha hecho de la vestimenta un elemento fundamental del trabajo, en algunas ocasiones es más importante esta que el trabajo mismo. Suele asociarse mucho el "éxito" en los negocios con el vestido, e incluso se ha acuñado la frase "vestirse para el éxito". El éxito material y sus correspondientes símbolos se convierten, en esta sociedad, en una verdadera obsesión. En otro sentido, el "vestirse para el éxito" se asocia con responsabilidad, seriedad, limpieza, que es lo que la persona menos favorecida en la escala social puede aprovechar para ocupar un lugar en el mundo del trabajo. Las asocia- 
ciones de carácter negativo tienen que ver con desorden, descuido, suciedad, irresponsabilidad; falta de aseo en la ropa y en el cuerpo, falta de gusto al combinar las prendas. El uso inapropiado de la vestimenta se asocia con los defectos arriba mencionados; y que se cree que trascienden a la esfera laboral. Así: buen vestir $=$ buen desempeño laboral $=$ éxito $=$ riqueza $;$ mal vestir $=$ mal desempeño laboral $=$ fracaso $=$ pobreza .

Aparentar "pobreza" puede incluso ser criminalizado, tanto por la sociedad como por el Estado mismo. Quien viste mal (sucio, pobre, desordenado) frecuentemente no es sujeto de lograr un trabajo, no consigue pareja, no recibe buena atención y es visto como sospechoso por la policía y es asediado por los vigilantes de centros comerciales, etc.

\section{La librea moderna:}

\section{logos, cintas, pines y colores. La empresa y sus formas de herrar}

En la sociedad posmoderna se hace especialmente palpable la diferencia entre empleador y empleado. Existen reglas en cuanto a la vestimenta, que el empleado tendrá necesariamente que obedecer. Estas pueden ser dos tipos: a) Reglas relativas a cómo llevar la vestimenta y b) Prohibiciones en cuanto a la vestimenta misma. Las reglas tradicionales del vestir en el trabajo - referido al trabajo de oficina-, tradicionalmente han hecho hincapié al uso de un uniforme, la disposición del cabello y el arreglo personal. En hombres: camisa manga larga, corbata, zapatos lustrados, pelo corto, no barba, limpieza general. En mujeres: traje "sastre" o "vestido", zapatos de tacón, cabello muy bien peinado, no maquillaje escandaloso, no dar impresión de demasiada sensualidad, limpieza general.

Actualmente se habla de que el trabajador refleja la imagen de la empresa. Con base en esta nueva forma de ver la relación de trabajador y vestido, el mundo del comercio ha ligado los colores y emblemas de la empresa al cuerpo del trabajador. Así pues, la empresa privada ha hecho de la camisa o camiseta no solo parte de un uniforme, sino además un medio de proyección y propaganda. El empleado se convierte así en "anuncio ambulante". Otra costumbre generalizada en nuestro medio consiste en que las camisetas, camisas y gorras suelen elaborarse en masa y regalarse a los empleados en fechas como Navidad. De esta manera la "imagen" de la empresa sale del ambiente meramente laboral y pasea por todos los rincones del gran San Salvador. 
En la escala laboral, quien ocupa el lugar más "bajo” tendrá un uniforme con características particulares; y revela intencionalmente su lugar dentro de la pirámide organizacional. Los empleados de limpieza y las empleadas domésticas usan un uniforme de características universales. Generalmente su uso se vuelve obligatorio en el lugar de trabajo. Así, más importante que el orden, el decoro y la "seriedad" es la identificación que el cliente haga del empleado con la empresa, el lugar que el empleado ocupa dentro de la cadena alimenticia organizacional. El empleado debe estar consciente de su condición de subalterno y usar los símbolos que lo acrediten como tal.

Las prohibiciones, en cuanto a la vestimenta en el lugar de trabajo, algunas son de carácter tradicional y generalmente obligatorias, algunas dependerán del capricho particular de cada empresa. En los hombres: uso de cabello largo, falta de corbata, no tatuajes, etc. En las mujeres: no mostrar en demasía el cuerpo, no sensualidad, etc.

\section{División social: el estilo, lindero de clase}

La ropa que usamos expresa en gran medida nuestra capacidad adquisitiva. En la sociedad neoliberal y posmoderna las personas se dividen de acuerdo con el grado de "éxito" que se expresa en cuatro símbolos: a) lugar y calidad de residencia (posesión de bienes inmuebles), b) personas y lugares que se frecuentan, c) ropa que se usa y d) posesión de bienes muebles: vehículos, electrodomésticos, artefactos tecnológicos. El éxito, pues, se expresa a través de la vestimenta, lo que lleva a que algunas persona "simulen" su posición dentro del sistema, es decir, a aparentar - a través de la vestimenta - tener más de lo que realmente tienen.

No obstante, las personas entrevistadas hacen énfasis en que buscan "calidad" al momento de adquirir una prenda. Calidad es el término general que se usa para describir características deseables en un producto. La significación de este término varía de persona a persona, aunque en términos generales esta se asocia con: a) sensaciones físicas que produce en la persona, b) lugar donde se compra y precio, y c) vida útil de la prenda.

\section{Las marcas y las tiendas}

La Gran Vía, el centro de San Salvador y Plaza Mundo constituyen centros proveedores de ropa para estratos sociales bien definidos y con características 
propias. La Gran Vía es uno de los centros comerciales donde las personas con mayores ingresos suelen comprar. En esta destacan dos tiendas: Simán (que ofrece las marcas Tommy Hilfiger, Lacoste, Polo, Ann Taylor, Gap, Liz Clairbone) y Zara, que su estilo es mas "juvenil” y los diseños de sus prendas son menos "serios" y se asocia con un estilo "europeo". Ambas tienen como mercado meta a personas con cierto poder adquisitivo.

En el centro de San Salvador existen locales propiamente dichos donde se vende ropa. También en la calle o lo que comúnmente se conoce como "metrosuelo" o "el agachón", que domina la venta no solo de ropa, sino también de todo el comercio informal en el centro; y las tiendas de ropa usada. Además, los mercados y los "mercaditos de pulgas" proveen de vestido a las personas. La ropa que más se vende en el centro de San Salvador es la "china”, la cual es "ropa pirata". Gracias a la ropa "china" un joven de escasos recursos puede vestirse "juvenil" y "a la moda", invirtiendo una módica cantidad.

Plaza Mundo se ha convertido en centro de consumo para la sociedad soyapaneca e ilopanense, además de atraer personas de San Martín, Cojutepeque, San Rafael Cedros, entre otros. La tienda Prisma Moda es uno de los principales centros de abastecimiento. Recientemente Carrión se ha convertido en otro proveedor importante. La calidad de prendas que se encuentran en estas tiendas es inferior a la de sus similares en otros centros comerciales.

\section{La ropa usada (USAda)}

No cabe duda de la importancia del mercado de ropa usada en los últimos años no solo como una solución a la necesidad del vestido, sino que ha permitido a un gran porcentaje de la población a integrase al proceso de globalización. Esta tiene un efecto igualador: las personas de ingresos elevados llevan ropa "de marca", a la que los pobres solo pueden tener acceso si es de segunda mano. El resultado es que una joven de una familia pobre es visualmente igual a la de una familia de clase media, pues sus diferencias se ven reducidas al menos en un plano simbólico

La ropa usada forma parte de la globalización del consumo, se importa en fardos (paquete o saco grande con cierto número de piezas), tanto de prendas interiores como exteriores. Estos fardos proceden de Estados Unidos, y hay empresas que se dedican a distribuirlos a las tiendas de "ropa americana". La ropa usada hace papable dicha globalización. Sin esta ropa el porcentaje de 
la población que participaría en el proceso sería menor, pues la ropa usada preferida es la que "ven por TV" en las series estadounidenses. Películas de Hollywood o las telenovelas mexicanas proporcionan modelos y fuentes de inspiración para el vestir. La ropa usada permite a la gente de bajos ingresos tener acceso a prendas que - según ellos - "solo los ricos pueden comprarlas nuevas".

El mercado de ropa americana ha crecido notablemente en el centro de San Salvador. Esto se debe principalmente a la gran demanda de esta clase de ropa. En tiendas grandes como la "Mega Boutique" puede verse, desde tempranas horas (mucho antes de que abran la tienda), gran cantidad de revendedores esperando abastecerse de prendas. Gracias al comercio de este tipo de ropa, gran cantidad de personas han tenido la sensación de haber ascendido de estatus. Este hecho no es consecuencia de un crecimiento económico ni de la reducción de la pobreza, sino de la globalización del comercio y de la reciente disponibilidad de bienes de alto contenido simbólico, los cuales han hecho que aquellas diferencias "marcadas" de clase, que revelaban los orígenes sociales de una persona a partir del vestir, se hayan vuelto menos evidentes.

\section{División por edad:}

\section{"Busco un sweater de viejito"}

La sociedad posmoderna hace especial énfasis en la edad de las personas al momento de clasificarlas y asignarles papeles. Estos pueden también hacerse evidentes en la vestimenta que el sistema ha asignado - como manifestamos arriba - a cada edad. El estilo "juvenil" ocupa un lugar destacado en el mercado. La juventud es una característica deseable por las personas en general. De hecho, se dice que actualmente existe un "culto a la juventud". Esta se asocia con dos cosas: 1) salud y vitalidad y 2) goce pleno de la sexualidad. El vestirse "juvenil", entonces, reporta un valor agregado a la persona y la hace acreedor de ventajas sociales, principalmente en el plano sexual. Sin embargo, existen sanciones cuando el individuo cruza la frontera que divide al ser humano por edades.

La sociedad posmoderna ha sido relativamente flexible en este criterio de división. Hoy en día se acepta que adultos de mediana edad puedan vestirse "juvenilmente", incluso se ha creado todo un mercado para conservar la juventud el mayor tiempo posible: gimnasios, suplementos vitamínicos, cremas, cosméticos, cirugía, etc. 


\section{División sexual: \\ "Rosado para niña, celeste para niño"}

En una cultura tradicionalmente conservadora como la salvadoreña los papeles masculino y femenino se expresan a través de la vestimenta, que crea determinadas actitudes en cuanto al papel de "hombre" o "mujer". Existen prendas tradicionalmente masculinas y prendas tradicionalmente femeninas. El uso de las prendas propias para cada género y los usos y comportamientos que la sociedad espera definirán el carácter hombre o mujer. La violación de estos papeles código atrae una sanción social que condena al trasgresor, atribuyéndole una calidad que varía de acuerdo con el género; pero siempre trae un cierto grado de marginación, burla e incluso violencia.

Para el caso de la mujer, existe una clasificación "moral" que se debe dejar ver a través de la vestimenta. Es una clasificación referente a la moralidad sexual. En El Salvador se usan las palabras honesta y deshonesta para esos propósitos. La "deshonestidad" en las mujeres es asociada con la ligereza en las costumbres sexuales y con el ejercicio de la prostitución. La sociedad posmoderna, no obstante, ha mostrado una apertura progresiva en cuanto estratificación de géneros, puesto que existen ahora prendas de mujer que pueden vestir los hombres y prendas de hombre que pueden vestir las mujeres. Claro, cada prenda respeta un estilo específico para cada género.

\section{Tendencias posmodernas del vestir}

\section{Moda reguetón: el blin de la remesa cultural}

Estilo relacionado con un tipo de música (reggae, un género musical de origen jamaicano). Aunque no tiene su origen en ella, ha hecho las delicias de los salvadoreños en la última década. El estilo reguetonero se asocia en gran medida con pandillas y tiene la pobreza y la marginación urbana como fuente primigenia de los símbolos que ostenta. La sociedad salvadoreña de la posguerra se caracteriza precisamente por la gran cantidad de salvadoreños que residen en los Estados Unidos y que hacen del envío de remesas el principal soporte económico del país. Estas remesas no solo son económicas, sino también culturales, por lo que el estilo reguetonero probablemente sea producto de la adhesión del "hermano lejano" a estos estilos vigentes en ciudades como Los Ángeles o Nueva York. 
El estilo reguetonero goza de popularidad, principalmente en sectores llamados "populosos" del gran San Salvador. En Soyapango e Ilopango puede notarse una preferencia singular por esta manera de vestir. Sin embargo, en La Gran Vía no es común encontrar jóvenes vestidos con estas características. De hecho, no se ven.

El reguetón, versión latina del hip hop (como estilo de vestir) tiene dos connotaciones: a) en su estado puro refleja el éxito material al que pueden acceder las clases marginadas. Sin importar cómo, se hacen acreedores del éxito económico y ostentan al máximo estos símbolos. Joyas, autos, licor y mujeres son sus aspiraciones. $\mathrm{Su}$

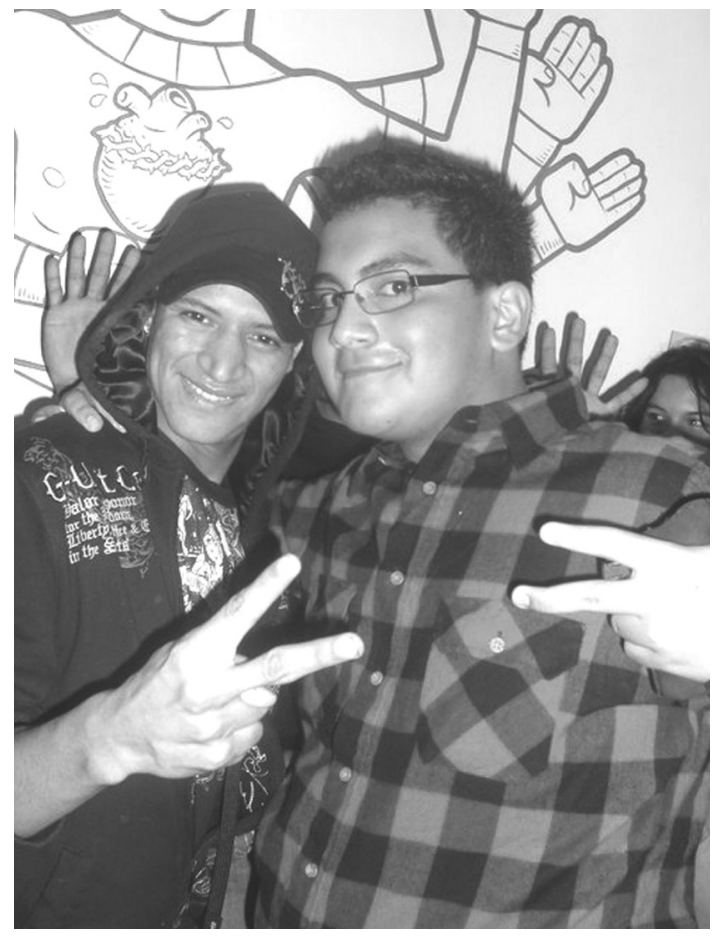

Este estilo es un reflejo de la importación de modas, basado en un género de música: el reguetón. filosofía de vida consiste en gastar la mayor cantidad de dinero en una noche. Su lema: "El dinero nos hace iguales"; b) en su estado "salvadoreño" es producto de la asimilación cultural que el "hermano lejano" hace del estilo más marginal de la sociedad estadounidense, y que "remesa" (envía) esa tendencia a sus compatriotas.

\section{Moda yuppie:}

\section{los "esen boys" a la vanguardia de la moda}

La aspiración y fin último del yuppie (acróstico de young urban professional o "joven profesionista urbano") es el éxito profesional a través de la escala de posiciones dentro de la pirámide organizacional de la empresa. Es sumamente competitivo, condiciona su forma de vestir y de actuar conforme al código de la cultura empresarial propia de cada país. El éxito profesional se evidencia en la adquisición de los símbolos que la sociedad actual ha asignado a ello: ropa de marca de elevado coste y comprada en tiendas exclusivas o en el extranjero, autos de modelos recientes, accesorios tecnológicos de vanguardia y elevado coste; el uso de servicios financieros, tales como tarjetas de crédito, 


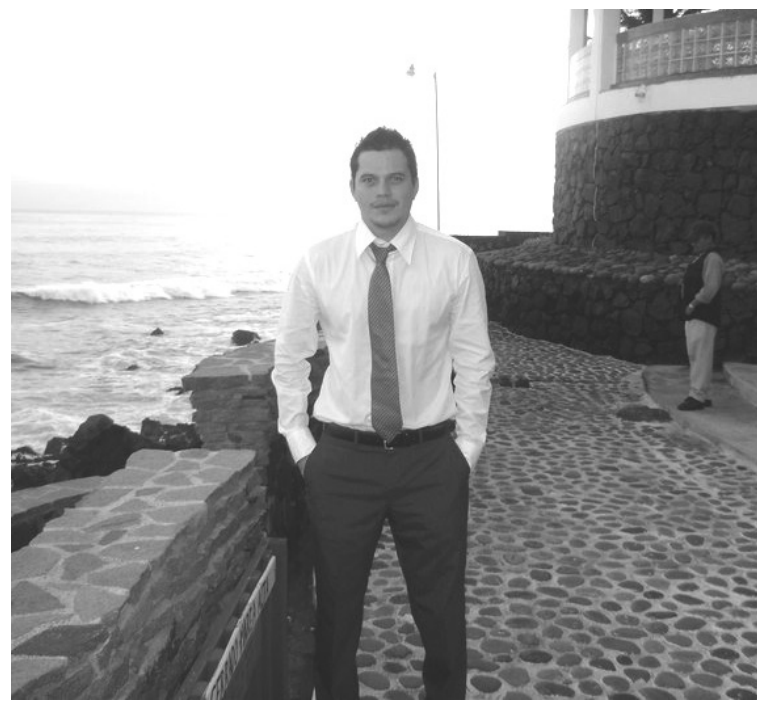

Los yuppies mantienen la tendencia de mostrar la imagen de éxito a través de su vestimenta. asiduidad a restaurantes exclusivos, clubes, etc.; consumo de cuanto artículo el mercado pone a su disposición y adhesión a las modas no solo en el vestir, sino también culturales, etc.

El yuppie salvadoreño ha hecho espacio de convivencia y esparcimiento los centros comerciales, especialmente dos: Multiplaza y La Gran Vía, lugares donde suelen reunirse y hacer vida social. En la esfera laboral el yuppie respeta el código que la cultura organizacional impone. La desviación de este a las reglas le hace acreedor del ostracismo por parte de quienes le rodean en ese ambiente, y lo hacen "no elegible" para la consecución de los tan "anhelados" ascensos. El estilo que se debe seguir en la esfera laboral debe ser sobrio, conservador (excepto en sectores específicos, como es la publicidad).

En actividades especiales, principalmente de la empresa, el yuppie mantiene su tendencia a mostrar la imagen del "éxito". Es una esfera muy importante dentro del mundo empresarial, se considera la asistencia de carácter obligatoria y es campo de acción útil para el desempeño de sus funciones para con la empresa. Los actos en cuestión sirven principalmente para realizar "cabildeo organizacional”. En ellos se atan los ascensos, se cierran negocios, se hacen contactos e inclusive se corteja y seduce.

El yuppie se expresa a través de las marcas. Básicamente nos dice dos cosas: 1) Su estilo particular: conservador y "serio". Algunas yuppies hacen del uso de ropa de Zara su manera de expresar preferencia por el estilo "europeo". De hecho, algunos llegan al extremo de compran su ropa en Europa, y se jactan de usar marcas desconocidas en el país, como H\&M. 2) El coste de la prenda y el lugar donde se compra es directamente proporcional al éxito material que posee. Mayor precio $=$ mayor éxito $=$ mayor prestigio. Es impensable para un yuppie el uso de "ropa usada" o ropa nueva comprada en locales del centro de San Salvador. 


\section{Moda pussy:}

\section{“in \& out”, el mundo según el adolescente}

El estilo pussy es uno que, al igual que el estilo yuppie, intenta expresar el grado de éxito material que se posee. Este estilo pertenece exclusivamente a adolescentes. El pussy es un adolescente obsesionado por la moda (fashion victim) y por la posesión de objetos materiales, además de depender su autoestima de la opinión de las demás personas, catalogándolo en categorías como "in \& out" dependiendo de la forma en que se viste, los grupos a que pertenece y la apariencia o no de poseer riqueza. Su "onda” es lograr la admiración de sus compañeros de colegio, que todos quieran ser sus amigos aunque sea él quien escoja a sus amistades. Dan especial importancia a la belleza física acorde al modelo occidental.

El pussy está al tanto de la moda, y su estilo es mutable. En realidad, no tiene un estilo definido; él depende de la moda en vigencia, y en una sociedad posmoderna la moda es mucho más transitoria.

\section{Moda bohemia:}

\section{"Nosotros los cultos, los intelectuales"}

Estas personas expresan, a través de la totalidad de su vestir o con algún aditamento o accesorio en su cuerpo, su oficio de artista, intelectual, humanista o miembro de una ONG, universidad o simplemente su pretensión de serlo. Este estilo en el vestir representa una posición antisistema, no en cuanto a una posición política, sino más bien en contra de un sistema tradicional de usos y costumbres, que en opinión de muchos tiende a uniformizar a la sociedad, negando las diferencias que, en un mundo globalizado, se acentúan y persisten, que no pueden

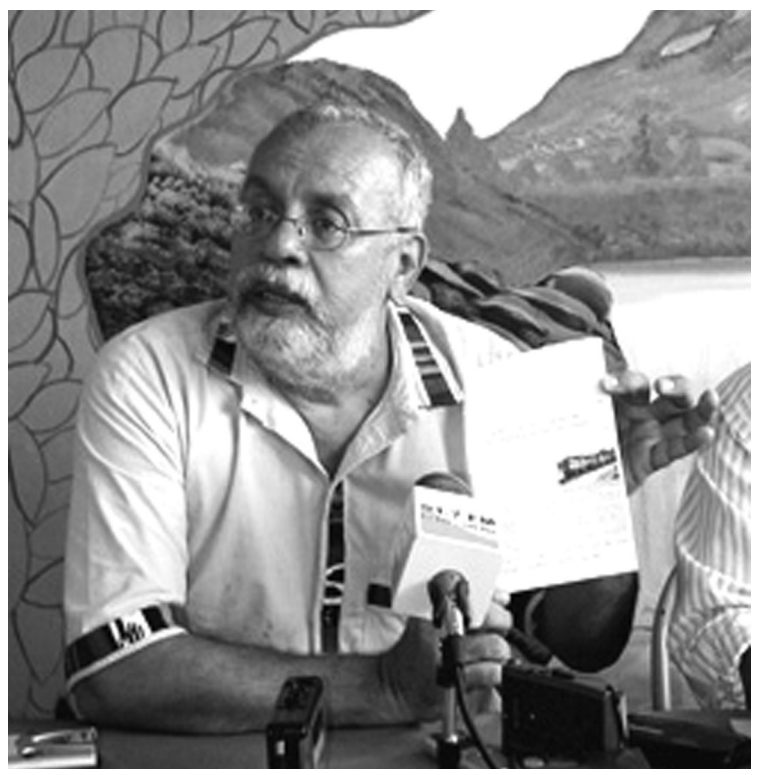

Estas personas expresan por medio de su estilo de vestir su oficio de artista, intelectual y humanista. 
ser obviadas. Si se quisiera resumir en pocas palabras esta aspiración, sería así: "Yo soy diferente". Comparten una característica común: se niegan a participar en el juego laboral tradicional y su rigidez en cuanto a la vestimenta.

En el centro de San Salvador puede encontrarse camisas hechas de manta, las prendas con motivos "chapines", collares hechos a mano, por parte de artesanos, ya sea de piedras, tallados en madera o resina, y cuyos motivos van desde animales, indígenas, religiosos hasta símbolos diversos, prendas teñidas con añil, etc. Una tendencia de reciente aparición en el país es la que ostentan muchos artistas jóvenes, especialmente artistas teatrales, que ha desarrollado un estilo no original, sino apegado a una manera de vestir propia de artistas callejeros con orientación al payaso y al circo. Una combinación de teatro y circo, que tiene como escenario las calles y hace uso de técnicas como el malabarismo, el payaso, los zancos y otros. Estos jóvenes usan ropa de colores llamativos, holgada, comprada generalmente en tiendas de ropa usada.

\section{Rockers:}

\section{Fenastras, la pasarela del rock en San Salvador}

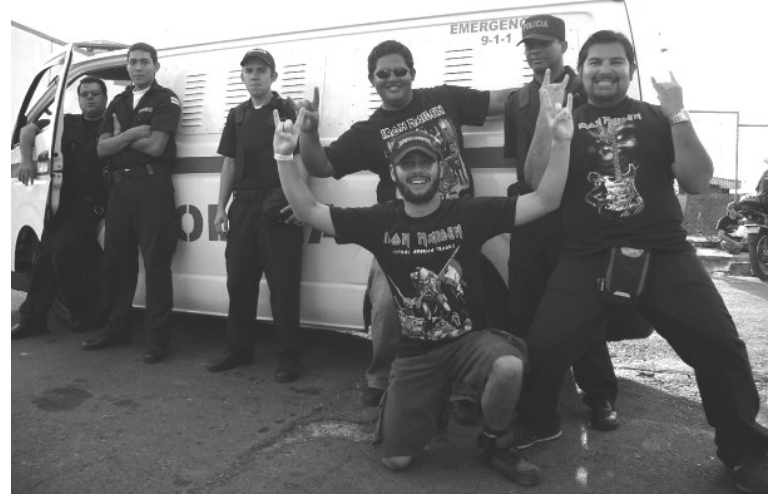

Más que ser considerado una moda el "rocker" es un estilo que encierra una actitud de desafió a las normas sociales establecidas.
El rocker no deja de estar presente en la globalizada sociedad salvadoreña. Más que ser considerado una "moda", quiere ser considerado como portavoz de un "estilo de vida", estilo que es de los pocos que tienen en un "genero musical" su raíz y su por qué. El rock (género musical de ritmo marcado, derivado de una mezcla de diversos géneros de música folclórica estadounidense) desde sus comienzos ha adoptado una actitud "contra-sistema", no contra valores políticos sino contra los valores sociales y culturales de sistemas sociales tradicionalmente cerrados, que niegan diferencias y que imponen al joven estilos de vida no acordes a la realidad que le ha tocado vivir. El rocker ha desarrollado un sentimiento de pertenencia a su "comunidad" y aspira a: 1) tener un espacio donde se le respete y logre desarrollar sus capa- 
cidades, manteniendo su forma de vestir y sus costumbres y 2) reivindicar su "música", encontrar un espacio en el universo musical de El Salvador donde los músicos puedan crear su obra, difundirla e incluso vivir de ella.

Se ha logrado, a través de la investigación de campo, identificar tres grupos importantes que diferencian a los rockers: 1. Rocker auténtico, que es aquel que interioriza los valores propios del rock como cultura. 2. Rocker ocasional, aquel que, si bien se adhiere a los usos y costumbres de la cultura rock, no interioriza los valores de esta. 3. Los rockers light. Son aquellos que pertenecen a clases más acomodadas y suele vérselos en centros comerciales. Compran las prendas propias del rock, pero en tiendas especializadas donde los costes son mayores, o las adquieren en el extranjero. Compran discos originales, no piratas. No asisten a los conciertos en Arena El Salvador, sino en Multiplaza o los establecimientos nocturnos de San Salvador, por ejemplo Malibú.

Algunas características de la vestimenta del rocker son: camisetas negras impresas con la portada del algún disco de ciertos grupos de rock, botas Harley o similares, chaquetas de cuero negras, tatuajes, cabello largo. Accesorios: pulseras negras, colgantes, llavero de cadena. En mujeres: labios y uñas pintados de negro, camiseta negra al igual que los hombres.

\section{Tendencias emergentes:}

\section{emos, rastafaris, neopunk y góticos:}

uñas negras, suicidas y marihuana. Los hijos de la sociedad del 2000

La sociedad globalizada ha dado lugar a la exportación de una innumerable cantidad de tendencias y estilos de vida. A escala global, podemos decir que existe un estilo de vida para cada persona del planeta. Algunas de estas tendencias son: neopunks, emos, rastafaris, lolitas, fanáticos del anime, góticos, entre otros. La característica común de estas tendencias es la ausencia de sesgo político y de reacción contra la sociedad tradicional. Tienden a ser más conformistas y buscan "vivir la vida". En casos extremos pueden llegar a ser cerrados en la aceptación para con los demás.

\section{Emos}

Esta tendencia da especial importancia a la apariencia física y a la vestimenta. Cabe decir que un verdadero emo solo puede pertenecer a clases sociales 
"privilegiadas", pues sus accesorios son de coste elevado y su estilo de vida tiende más a la evasión y a "vivir la vida". Algunas características de estos son: apariencia andrógina, la vestimenta, muy ajustada al cuerpo, para hombres y mujeres no tiene mayor variación; uso de símbolos: calaveras, grilletes y corazones flechados; prefieren los colores rosado y negro; zapatos tenis estilo All Star, pero deben lucir gastados; prefieren los de marca Van (bastante caros); pelo largo (no demasiado), liso dispuesto de manera que caiga en el rostro y lo cubra; delgadez extrema y altura mínima para hombres $1.70 \mathrm{~m} \mathrm{y}$ para mujeres 1.60 .

\section{Rastafaris}

En El Salvador encontramos algunos representantes de esta "moda" en centros comerciales, aunque se les puede ver en diversos puntos de San Salvador. Generalmente se asocian bastante con la venta en la calle de artesanías que ellos mismos elaboran, y que ha tenido bastante éxito ante el comprador salvadoreño. Ahora bien, no todo rastafari es artesano. De hecho, se les conoce popularmente en esta faceta. Podemos identificar a los rastafaris a través de la combinación de colores concordantes con la bandera de Jamaica: verde, amarillo, rojo y negro; los símbolos de sus camisetas y demás prendas: la efigie de Bob Marley y la hoja de marihuana, gorros amplios para cubrir las rastas, cabello en forma de rastas; look playero: short o bermuda, camiseta con los motivos antes señalados, morrales con los colores correspondientes, sandalias, pulseras y colgantes de colores vivos y llamativos con el símbolo de la hoja de marihuana. Suelen usar piercing (perforaciones).

\section{Neopunks}

Recogen la parafernalia del punk tradicional, aunque dejan de lado el color negro y los accesorios militares. Es un estilo asociado a un género musical, el punk. Y aunque su temática aborda temas de carácter social, está bastante alejado del espíritu "contestatario" de la versión original de este. Actualmente en El Salvador existen algunos grupos que tocan este género de música y organizan "conciertos" en pequeños establecimientos de reciente inauguración. Es el caso de antros como "Kamikaze" o "Tequileros". Sus miembros son pocos, y es raro verlos en la calle. Causan un asombro al salvadoreño común que, no acostumbrado a las diferencias, prefiere ver de reojo y callar cuando algún joven de estos visita un centro comercial. 


\section{Góticos}

En El Salvador es raro encontrar una vestimenta gótica pura. Sin embargo, se evidencia entre mujeres que suelen pintarse las uñas, los labios y las cejas de negro. Algunas usan un exceso de base facial que les confiere una tonalidad pálida. Es común que muchas mujeres rocker no se definan como tales, sino más bien como góticas.

\section{La picaresca:}

\section{"Busco novia coja, entre más coja mejor"}

Las camisetas con mensajes "de doble sentido" se crearon en la década de los 80, precisamente como souvenir. Los comercializaba la tienda "Nahanché", ubicada en Metrocentro, y no eran precisamente de doble sentido, sino más bien caricaturas (horribles por cierto) que exaltaban los malentendidos valores culturales salvadoreños: pupusas, fútbol, cerveza y cóctel de conchas. "Los salvadoreños somos "cachimbones"”; "Los guanacos "echamos riata". Estas camisetas eran creadas para el turista norteamericano o europeo, o para ser enviadas como obsequio al "hermano lejano".

Este tipo de prenda - a través del mensaje de doble sentido que casi exclusivamente tiene impreso - refleja parte del sentir y pensar de la mayoría silenciosa que conforma el pueblo salvadoreño. El contenido de sus mensajes tratan, de un modo jocoso y hasta cierto punto simple, algunas realidades que podrían agruparse así: mensajes de contenido sexual explicito, mensajes de contenido político y mensajes exaltando el valor "cultural" salvadoreño. La ropa picaresca en sí refleja un sentir de este pueblo, y trata de expresar una identidad, cualidades y características. Es una manera de ver, de una forma "muy particular", lo que se considera esta cultura.

\section{Conclusión}

El Salvador se va convirtiendo, poco a poco, en un crisol que alberga un número cada vez mayor de tendencias sociales, que adoptan determinados usos y costumbres; y que reflejan el deseo de las personas de diferenciarse a través de las particulares maneras de vestir de cada una de ellas. Todo esto va creando paulatinamente pequeñas industrias que aportan a la economía familiar y que van convirtiéndose en un rubro importante de la economía nacional. Así 
mismo, esto indica una tendencia cada vez mayor a cuestionar los valores tradicionales y a buscar más apertura y aceptación de la sociedad; primero de las personas, luego del Estado.

Finalmente, podemos decir que, si bien es cierto que cada sociedad tiene reglas en cuanto a la manera de vestir y la ocasión en que se usen ciertas prendas, también en una sociedad globalizada se debe aceptar que cada día es mayor el grado de diversidad. Debe revisarse y estudiarse las actitudes que genera la vestimenta en particular, y proponer soluciones que impidan la marginación o la exclusión de las personas con base a su forma de vestir.

\section{Referentes bibliográficos}

- Alcaldía Municipal de Antiguo Cuscatlán. Directorio turístico [en línea] San Salvador [Mayo 2008] www.antiguocuscatlan.gob.sv.

- Bailian de Tagtachian,B.. Un componente del tercer sector. 1er encuentro de investigadores sobre el tercer sector de América Latina y El Caribe de ISTR. Río de Janeiro. 2006.

- Barfield, T. y Schussheim, V. Diccionario de Antropología. México D.F. Editorial: Siglo XXI, 2000.

- Bonte, P. E. Izard, M. Diccionario Akal de Etnología y Antropología. Madrid. Editorial: Akal, 2005. pp. 200-209.

- Capron, G y de Alba, M. Fábrica de sueño suburbano de clase media en la ciudad de México. 2do coloquio internacional sobre imaginarios urbanos. Universidad Autónoma Metropolitana - Iztapalapa. 2007.

- Carreno Martínez, A. La Prisión del Vestido. Aspectos sociales del traje en América. Bogotá. Editorial: Planeta colombiana. 1995.

- DUNN, S. Metal: A headbager's journey. [DVD]. Universal films. Canadá. 2005.

- ECO DORFLES, U. Psicología del vestir. Barcelona, Lumen. 1976.

ELJURI JARAMILLO, G. La Seda y El Vestir. [En línea] [Abril 2008] http://www.ciudap. org.ec.

ENCARTA, El Salvador Encarta. Enciclopedia virtual [En línea] 2008, Microsoft. www. encarta.msn.com. 
- Exordio, Revista virtual. [En línea] 2001. [Agosto 11, 2008] www.exordio.com.

- GONZÁLEZ ARENCIBIA, M. La relación global-local: sus implicancias prácticas para el diseño de estrategias de desarrollo. Santiago de Cuba. [En línea] www.eumed.net.

- HEBDigE, D. Subcultura, el significado del estilo. $2^{\text {a }}$ edición. Editorial: Paídos Ibérica. Barcelona. 2004.

- HERNANDEZ, G. y BARRERA, J. La Gran Vía un nuevo mundo de diversión y compras. El Diario de Hoy, 6 de diciembre del 2005, San Salvador, El Salvador. Pp.41

- HERRERA ROMERO, N. Reflexiones sobre modernidad, posmodernidad y cultura en Venezuela. [En línea] www.misioncultura.gob.ve.

- KOTTAK, C. Antropología, una exploración de la diversidad humana $6^{a}$ Edición. España. Editorial: McGrawHill. 1994.

La ropa unisex. [En línea],[Junio 2008] www.contestandotupregunta.org/unisex1.htm.

- LE BRETON, D. Antropología del cuerpo y modernidad. $2^{\text {a }}$ Edición. Buenos Aires. Editorial: Nueva Visión SAIC. 1995.

- LYON, D. Postmodernidad.2 ${ }^{a}$ Edición. Editorial: Alianza. 1998.

- MANGIERI, R. El cuerpo como tema. Revista Heterogénesis. Universidad de Los Andes, Venezuela. 2003.

- MORENO, W. Plaza Mundo cumple la meta. El Diario de Hoy. 8 de octubre del 2008, San Salvador, El Salvador. Pp. 46

- PALACIO, J.; CORREA, A; DIAZ, M. Y JÍMENEZ, S. La búsqueda de identidad social, un punto de partida para comprender las dinámicas del desplazamiento-reestablecimiento forzado en Colombia. Centro de Investigaciones en Desarrollo Humano de la Universidad del Norte y COLCIENCIA. Revista: Investigación y desarrollo vol. 11 nº 1.2003.

- PASTTOUREAU, M. Las vestiduras del diablo. Breve historia de las rayas en la indumentaria. $2^{\text {a }}$ Edición. Editorial: Océano. Barcelona. 2005.

- PROCOMES. Diagnostico de gestión de residuos sólidos del Distrito Centro Histórico del Municipio de San Salvador, en período de 2005. San Salvador. El Salvador. 2005.

- SÁNCHEZ, S. Historias nómadas de un cuerpo híbrido y subversivo. El cuerpo de los tiempos. Sevilla. España, 2000.

- San Salvador, El Salvador. Centros urbanos. [En línea] [Febrero 2008]. www.urbalvictoria.gob.mx. 
- SARTRE, J. P. El ser y la nada. Madrid. Editorial: Magisterio Español. 1977.

- SCANDROGLIO, B.; LÓPEZ MÁRTINEZ, J. Y SAN JOSÉ SEBASTIÁN, MA. La teoría de la identidad social: una síntesis crítica de sus fundamentos, evidencias y controversias. Revista Psicotherma, vol. 20 n 1. Universidad Autónoma de Madrid. España. 2008.

- SQUICCIARINO, N. El vestido habla: consideraciones psico-sociológicas sobre el vestido. $2^{\text {a }}$ Edición. Madrid. Editorial: Cátedra. 1990.

- VÁSQUEZ ROCCA,A. La moda en la posmodernidad, deconstrucción del fenómeno fashion. Articulo para la revista Crítica de Ciencias Sociales y Jurídicas. Universidad Complutense de Madrid. España. 2005.

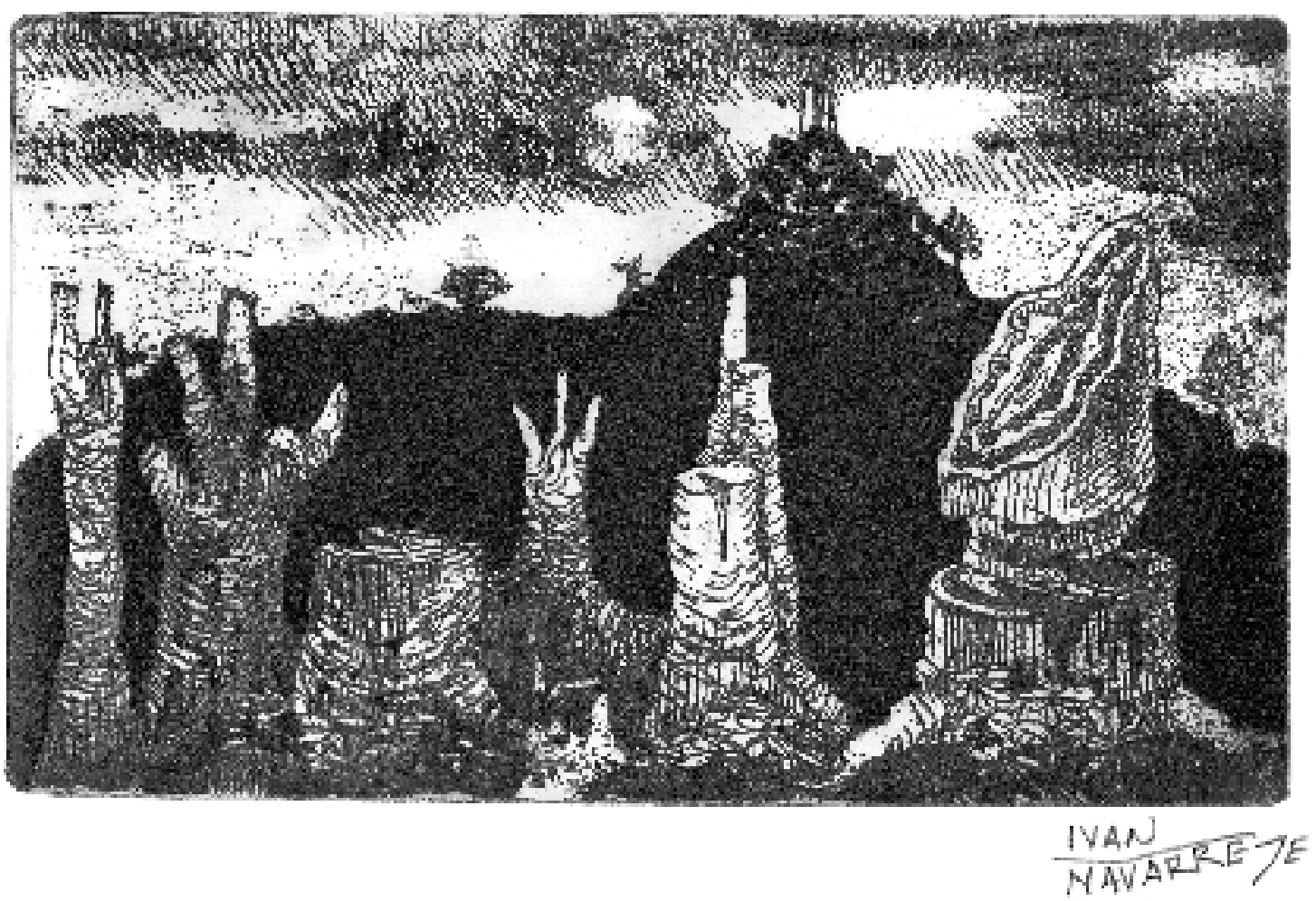




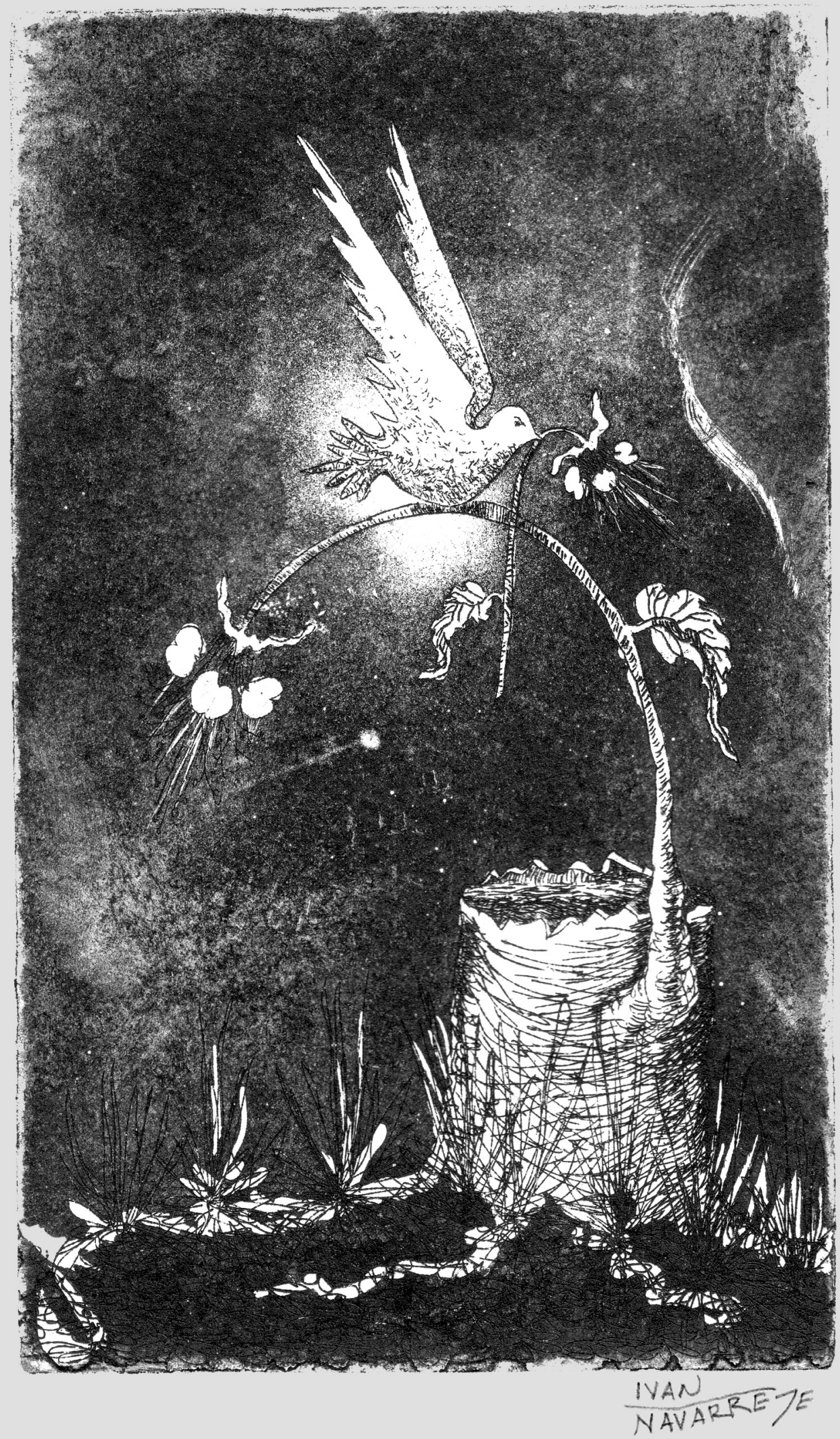




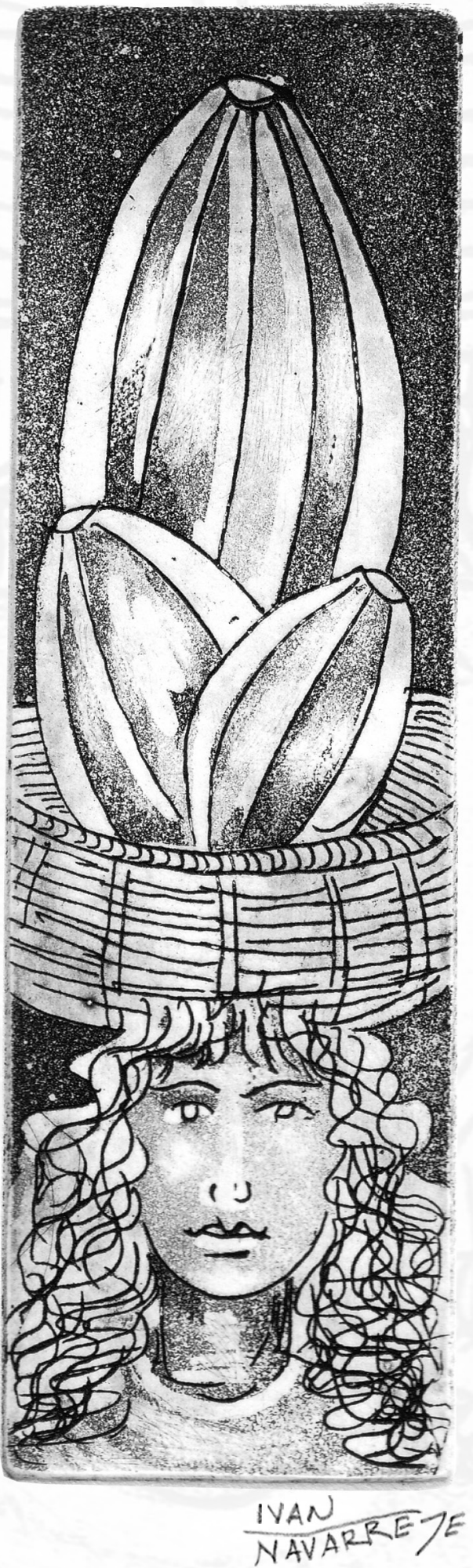

